\title{
Topraksız Tarımda Kullanıldıktan Sonra Açığa Çıkan Ortamların Marul ve Maydanoz Fidesi Yetiştiriciliğinde Kullanımı
}

\author{
Salim TAŞDELEN ${ }^{1}$, Aslıhan ÇİLINGİR TÜTÜNCÜ ${ }^{1 *}$, Harun ÖZER ${ }^{1}$
}

\section{ÖZ}

$\mathrm{Bu}$ çalışmada; topraksız yetiştiricilikte domates ve marul üretiminde kullanıldıktan sonra açığa çıkan 4 ortamın [domates atıkları (DA; doğrudan kullanılan, ÖDA; ön işlem gören), Hindistan cevizi lifi $(\% 100)$, Torf + Perlit karışımının (\%65+\%35)] marul (Lactuca sativa var. capitate) ve maydanoz (Petroselinum crispum) fidesi yetiştiriciliğinde kullanım durumu test edilmiştir. Kontrol ortamı olarak torfun kullanıldığı çalışma, sonbahar döneminde 1 sıtmasız cam serada yürütülmüştür.Yetiştirme ortamlarının gövde çapı $(\mathrm{mm})$, fide boyu $(\mathrm{cm})$, kök uzunluğu $(\mathrm{cm})$ ve fide yaş ağırlığı $(\mathrm{g})$ üzerine önemli etkileri belirlenmiştir $(\mathrm{p}<0.05)$. Marul ve maydanoz fidelerinin kalitesinde DA ve ÖDA atıklarının diğer yetiştirme ortamlarına iyi bir alternatif olabileceği belirlenmiştir.

Anahtar Kelimeler: Domates atığı, kaliteli fide, Hindistan cevizi lifi, torf, perlit

\section{Uses of Released Media After Used in Soilless Agriculture in Lettuce and Parsley Seedling Cultivation}

\begin{abstract}
In this study; 4 media [tomato wastes (DA; directly used, ÖDA; pre-treated), coconut fiber $(100 \%)$, Peat + Perlite mixture $(65 \%+35 \%)]$ released after being used in tomato and lettuce production in soilless cultivation, lettuce ( Lactuca sativa var. capitate) and parsley (Petroselinum crispum) seedlings were tested for use. The study, in which peat was used as the control medium, was carried out in an unheated glass greenhouse in autumn. Significant effects of the growing medium on the stem diameter $(\mathrm{mm})$, seedling length $(\mathrm{cm})$, root length $(\mathrm{cm})$ and seedling fresh weight $(\mathrm{g})$ were determined $(\mathrm{p}<0.05)$. It has been determined that DA and ÖDA wastes can be a good alternative to other growing media in the quality of lettuce and parsley seedlings.
\end{abstract}

Keywords: Tomato waste, quality seedlings, cocopeat, peat, perlite

Orcıd ID (Yazar sirasına göre)

0000-0001-5326-6935, 0000-0002-7752-8976, 0000-0001-9106-383X

\footnotetext{
Yayın Kuruluna Geliş Tarihi: 22.10.2021

Kabul Tarihi: 03.12.2021

${ }^{1}$ Ondokuz Mayis Üniversitesi, Ziraat Fakültesi, Bahçe Bitkileri Bölümü, Samsun

*E-posta:aslihancilingir6155@gmail.com
} 


\section{Topraksız Tarımda Kullanıldıktan Sonra Açığa Çıkan Ortamların Marul ve Maydanoz Fidesi Yetiştiriciliğinde Kullanımı}

\section{Giriş}

Sebze yetiştiriciliğinde, üretimdeki riski en aza indirmek için doğrudan tohum ekimi yerine, fide dikimi ile üretime başlamak başarıyı artırmaktadır. Fide kalitesi yanı sira fide yetiștiriciliği için altyapı masraflarından kurtulmak, tohum kaybını azaltmak, üretime daha sağlıklı fidelerle girmek, üretim sezonunu daha iyi değerlendirmek ve işçilik masraflarını azaltmak amaciyla üreticiler tarafindan hazır fide kullanımı tercih edilmektedir (Tüzel ve ark., 2015; Özer ve Kandemir, 2016). Başarılı bir fide üretimini etkileyen en önemli faktörlerden bir tanesi yetiştirme ortamıdır. Günümüz fide yetiştiriciliğinde, yetiştirme ortamı olarak organik (torf, ağaç kabuğu, talaş, sap-saman ve Hindistan cevizi lifi) ve inorganik (kum, çakıl, perlit, vermikülit, pomza, kaya yünü ve zeolit) ortamlar kullanılmaktadır (Dönmez ve ark., 2016). Torf ortamının su tutma ve havalanma kapasitesinin yüksek olmas1 ve bitkiye ideal bir büyüme ortamı sağladığından ticari fide yetiştirme ortamı olarak tercih edilmektedir (Demiral, 2016).

Son y1llarda dünyada ve ülkemizde torf yatakları azalmaktadır. Bunun yanı sıra yerli torf kaynaklarımız kontrolsüz kullanılmakta ve bir standardı bulunmamaktadır. Bu nedenle ülkemizde her yıl büyük miktarda torf ithal edilmektedir (Çinkılıç, 2008). Diğer taraftan yetiștiricilikte kullanılan Hindistan cevizi lifi de doğrudan ithal edilen bir yetiştirme ortamıdır. Yetiştiricilikte kullanılan ortam maliyetin artmas1 üreticileri daha kolay ve ucuz materyaller aramaya yöneltmiştir. Ancak ülkemizde henüz sebze üretiminde fide yetiştiriciliği yapmak için standartlara uygun, kolay temin edilebilir ve ucuz bir yetiştirme ortamı bulunmamaktadır (Varış ve Eminoğlu, 2003).

Dünyada ve ülkemizde tarımsal üretimin artışıyla beraber bitkisel hasat atıkları ve tarımsal endüstri atıkları yıldan yıla artış göstermektedir. Söz konusu bitkisel kökenli atıkların kolay temin edilebilmesi, ucuz olması, içerdiği organik madde ve diğer bitki besin maddeleri yönünden zengin olmas1 fide yetiştirme ortamı olarak kullanılabilmelerinin yolunu açmıştır. $\mathrm{Bu}$ konuda yapılan çalışmalarda serada bitkisel üretim sonrasında ortaya çıkan bitki atıkları gibi organik kökenli atıkların yetiştiricilikte kullanımının bitki kalitesi ve verimi üzerine olumlu etkilerinin olduğu bilinmektedir (Özer, 2008; Dönmez, 2016; Polat ve ark., 2017; Y1lmaz ve ark., 2018). Bu atıklar içerisinde domates atı̆̆1, domates yetiştiriciliğinin yoğun yapılması nedeniyle ön plana çıkmaktadır. Durmuş ve Kizılkaya (2018), Antalya ilinde sadece domates yetiştiriciliği yapılan seralardan her sene 111.480.99 ton kuru madde olarak biyokütle atığının açığa çıktığını bildirmişlerdir. Özellikle topraksız tarım yapılan seraların önemli bir kısmında domates yetiştiriciliği yapıldığ1 düşünülmektedir. Domates atıklarının kat1 ortam kültüründe (yetiştirme ortamı olarak) kullanılması çevre kirliliğini önemli ölçüde önleyecek ve girdi maliyetlerini azaltacaktır. Ayrıca, bu ortamların diğer ticari ortamlar gibi birkaç defa yetiştiricilikte kullanılabilir olması verimliliği artıracaktır.

$\mathrm{Bu}$ çalışmada, topraksız tarımda önce domates takibinde marul yetiştirme ortamı olarak kullanılan domates atıklarının (DA ve ÖDA) ve ticari yetiştirme ortamlarının marul ve maydanoz fidesi yetiştiriciliğinde kullanım durumu araştırılmıştır.

\section{Materyal ve Yöntem}

Araştırma, Ondokuz Mayıs Üniversitesi Ziraat Fakültesi Bahçe Bitkileri Bölümü'ne ait cam serada Ekim-Kasım 2020 tarihleri arasında gerçekleştirilmiştir. Çalışmada bitkisel materyal olarak marul (Lactuca sativa var. capitate cv. 'Iceberg') ve maydanoz (Petroselinum crispum cv. 'D'Giant Italiana') çeşitlerine ait tohumlar kullanılmıştır.Araştırmada, domates atıkları (DA; doğrudan kullanılan, ÖDA; Ön işlem gören), Hindistan cevizi lifi (\%100), torf-perlit karışımı $(\% 65+\% 35)$ ve kontrol olarak torf ortamı olmak üzere 5 farklı yetiştirme ortamı kullanılmıştır. Çalışmada ele alınan domates atıkları, Hindistan cevizi lifi ve torf+perlit ortamlar1 topraksiz domates ve marul yetiştiriciliğinde kullanılmıştır. Topraksız yetiştiricilikte kullanılmadan önce domates atıkları öncelikle $(8 \mathrm{~mm})$ çekiçli tip değirmende öğütülmüştür. Öğütülen domates atıkları doğrudan (DA) ve ön işlem görerek (ÖDA) yetiştirme ortamı haline getirilmiştir. ÖDA 


\section{Topraksız Tarımda Kullanıldıktan Sonra Açığa Çıkan Ortamların Marul ve Maydanoz Fidesi Yetiştiriciliğinde Kullanımı}

ortamı (210 litre) için domates atığı karıșımı 1 $\mathrm{kg}$ üre, $3 \mathrm{~kg}$ ahır gübresi, $1 \mathrm{~kg}$ şeker, $5 \mathrm{~kg}$ toprak bulunan süspansiyon ile 1slatılmış ve iki ay boyunca şeffaf naylonla kapatılarak bir ön kompostlama işlemi yapılmıştır (Yörük, 2021). Çalışmada yetiştirme ortamı olarak kullanılan DA, ÖDA, Hindistan cevizi lifi ve torf+perlit ortamları ilk olarak topraksı domates yetiştiriciliğinde, sonrasında steril edilerek topraksız marul yetiştiriciliğinde iki kez kullanılmıştır. Topraksız yetiştiricilikte yetiștirme ortamı olarak kullanılan atıklar, çalışmada kullanılmadan önce otoklavda $121{ }^{\circ} \mathrm{C}$ sicaklıkta 1 atm basınçta 30 dakika steril edilmiştir. Tohum ekimi işlemi öncesinde ortamların $\mathrm{pH}$ metre (Adwa waterproof) ile $\mathrm{pH}$ değerleri, EC metre (Adwa waterproof) ile EC değerleri belirlenmiştir. $\mathrm{pH}$ ve $\mathrm{EC}$ değerleri ölçümü için ortamlardan 1:10 ortam/saf su bir behere alınarak süspansiyon hazırlanmıştır. Hazırlanan süspansiyonlar manyetik karıştırıcı üzerinde 1 saat çalkalanmış ve daha sonra $\mathrm{pH}$ ve EC değerleri ölçülmüştür (Çizelge 1).

Çizelge 1. Ortamların $\mathrm{pH}$ ve EC değerleri

\begin{tabular}{lcc}
\hline Yetiştirme ortamları & $\mathrm{pH}$ & $\mathrm{EC}\left(\mathrm{ms} \mathrm{cm}^{-1}\right)$ \\
\hline DA & 7.22 & 0.9 \\
ÖDA & 7.97 & 0.6 \\
Hindistan cevizi lifi & 7.66 & 0.31 \\
Torf + Perlit & 7.77 & 0.25 \\
Torf (kontrol) & 7.21 & 0.62 \\
\hline
\end{tabular}

Fide yetiştirme periyodu boyunca sera sıcaklık $\left({ }^{\circ} \mathrm{C}\right)$ ve oransal nem $(\%)$ (KT100, Kimo, Fransa) değerleri ölçülmüştür. Ölçüm değerleri ortalama, en yüksek ve en küçük değerler olarak Çizelge 2'de verilmiştir.

Marul ve maydanoz tohumları 5 farklı ortamda 3 tekerrürlü ve her tekerrürde 100 tohum olacak şekilde ekilmiştir. Tohumlar ekim ayında dış ölçüsü 668x330x50 mm, fide göz ölçüsü 26-26$45 \mathrm{~mm}$ olan 210 gözlü viyollere ekilmiştir.

Çizelge 2. Serada sıcaklık ve nem değerleri

\begin{tabular}{lccl}
\hline & $\begin{array}{c}\text { Hava sıcaklığı } \\
\left({ }^{\circ} \mathrm{C}\right)\end{array}$ & $\begin{array}{c}\text { Nem } \\
(\%)\end{array}$ & $\begin{array}{c}\text { Işık } \\
\text { (lüx) }\end{array}$ \\
\hline En yüksek & 23.5 & 97.6 & 5656 \\
En düşük & 20.8 & 48.9 & 181 \\
Ortalama & 18.3 & 71.5 & 2626 \\
\hline
\end{tabular}

Tohum ekimi yapılan viyoller 1sitma kontrollü cam serada yetiştirme tezgâhlarına yerleştirilmiş, yetiştirme periyodu boyunca günde 3 kere (saat:10.00, 14.00, 16.00) beşer dakikalık sulamalar yapılmıştır.

Marul ve maydanoz tohumlarının iki günde bir sayımı yapılmış olup, tekerrürlerin ortalamaları alınarak çıkış oranları (\%)hesaplanmıştır. Çıkış oranı, çimlenen tohum sayıs1/toplam tohum sayıs1 x 100 formülü ile belirlenmiştir. Tohumların çimlenip kotiledon yapraklarının toprak yüzeyine parelel olduğu aşama fidelerin çıkışını tamamladığ 1 kabul edilmiştir. Fide kalitesini belirlemek için fideler üç yapraklı aşamaya geldiğinde cetvelle fide boyu $(\mathrm{cm})$, kök uzunluğu $(\mathrm{cm})$, dijital kumpasla gövde çap1 (mm) ölçülmüștür. Yaprak klorofil içeriği CCI (Chlorophyll Content Index) klorofil metre (CCM-200, Opti-Sciences, Hudson, USA) kullanılarak her ortamdan alt1 fidede ölçülmüştür. Yaprak renk ölçümleri ise Minolta renk ölçüm cihazı kullanılarak L, a, b cinsinden ölçülmüş ve $\mathrm{Hue}^{\mathrm{o}}$ kroma değerleri aşağıdaki formüle göre hesaplanmıştır (McGuire, 1992).

$$
H_{u e} \mathrm{~h}=\tan ^{-1}(\mathrm{~b} / \mathrm{a}) \quad \text { Kroma } C^{*}=\sqrt{ }\left(\mathrm{a}^{2}+{ }^{\mathrm{b} 2}\right)
$$

Üç yapraklı döneme gelen fidelerin söküm işleminden sonra kökler yıkanmış, kök ve gövde olacak şekilde birbirinden ayrılmıştır. Kök ve gövdelerin yaş ağırlığ 1 (g) alınmış, daha sonra $80^{\circ} \mathrm{C}$ 'de 48 saat sabit ağırlığa gelinceye kadar kurutularak kuru ağırlıkları tespit edilmiştir (Peker ve ark., 2019). Elde edilen sonuçlara göre toplam fide kuru ağırlığı (g) belirlenmiştir.

Çalışma sonucunda elde edilen verilerin değerlendirilmesinde JMP istatistik analiz programı kullanılmıştır. Elde edilen ortalamalar arasındaki farklar LSD karşılaştırma testiyle belirlenmiştir $(p<0.05)$.

\section{Bulgular ve Tartışma}

Tohumlarda çıkış başlangıcı marulda tohum ekiminden 6 gün sonra, maydanozda ise 7-8 gün sonra gerçekleşmiştir. Marulda yetiştirme ortamlarına göre çıkış oranları farklılık göstermekle birlikte en yüksek tohum çıkış oranı torf ortamında (\%96) tespit edilmiştir. Bunu sırasıyla domates atığ 1 (\%91) ve ön işlem 


\section{Topraksız Tarımda Kullanıldıktan Sonra Açığa Çıkan Ortamların Marul ve Maydanoz Fidesi Yetiştiriciliğinde Kullanımı}

görmüş domates atı̆g1 (\%80) ortamları takip etmiştir. En düşük tohum çıkış oranı ise \%26 ile Hindistan cevizi lifi ortamında tespit edilmiștir. Tüm yetiştirme ortamlarında marul tohumlarının tohum ekiminden 6 gün sonra çıkış yapmaya başladığı ve 20. güne kadar doğrusal bir artış göstererek en yüksek çıkış oranına ulaştığ belirlenmiştir. 20. günden sonra ise kalan tohumlarda çıkış gözlenmemiştir (Şekil 1). Farklı yetiştirme ortamlarının maydanoz tohumlarının çıkış oranına etkisini

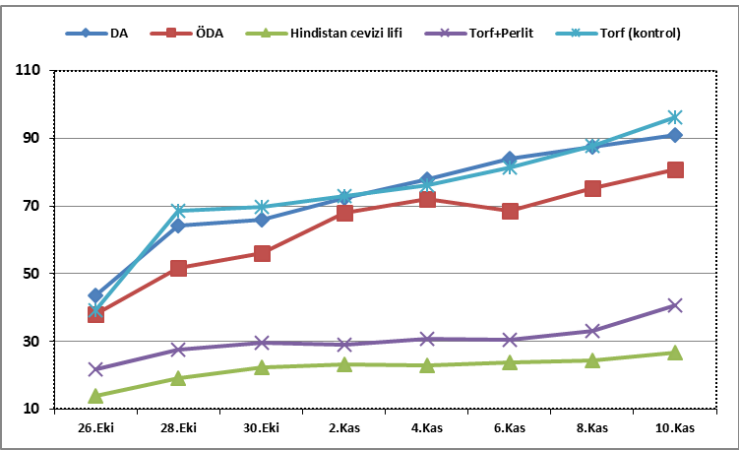

a incelediğimizde; en yüksek (\%100) ve en düşük (\%95) tohum çıkış oranları sırasıyla domates atığ1 ortamında ve torf ortamında tespit edilmiştir. Torf + Perlit ve ön işlem görmüş domates atığ 1 ortamlarında ise çıkış oranı $\% 98$ ile benzer olduğu gözlemlenmiştir. Yetiştirme ortamlarının tümünde tohum ekiminden 7-8 gün sonra çıkışlar başlamış, doğrusal bir artış göstermiştir (Şekil 1). 20. günün sonunda ise kalan tohumlarda herhangi bir çıkış görülmemiştir.

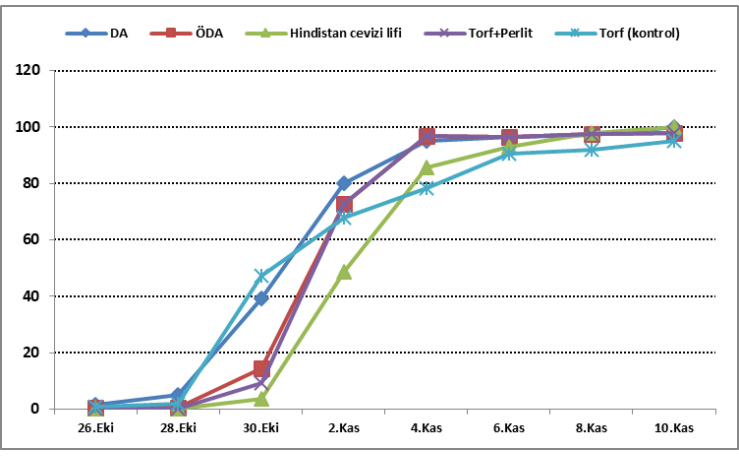

b

Şekil 1. Farklı yetiştirme ortamlarının marul (a) ve maydanoz (b) çıkış oranları

Çalışmada, tohum çıkış oranında DA ve torf (kontrol) ortamı ön plana çıkmıştır. Torfun düşük hacim ağırlı̆g 1 , su tutma kapasitesinin yüksek olması nedeni ile fide yetiştiriciliği için çok elverişli bir ortam olduğu bilinmektedir (Munsuz ve ark., 1982). Yapılan çalışmalarda, torf ortamında yetiştirilen fidelerin çıkış oranları yüksek olurken, kullanılan torfun tuzluluğunun yüksek ve besin maddesi kapsamının düşük olmasının fide gelişimini olumsuz yönde etkileyerek kaliteyi düşürdüğü bildirilmektedir. Torfun başarısını artırabilmek için besin solüsyonu ile güçlendirilmesi gerektiği ifade edilmektedir (Doğan, 2003). Yetiştirme ortamlarında yüksek tuz konsantrasyonu ve düşük porozitenin; tohum çimlenme, çııış ve fide gelişiminini olumsuz olarak etkilediği bildirilmektedir (Atiyeh ve ark., 2000; Namal, 2019). Araştırıcıların bulgularına benzer olarak en düşük tohum çıkış oranı, yüksek tuzluluk değerine sahip DA ortamında belirlenmiştir. Çimlenme üzerinde etkili olan önemli faktörlerden bir tanesi de nemdir, bunun içinde ortamın havalanma ve su tutma kapasitesi özellikleri önem taşımaktadır (Özer, 2018; Namal, 2019). En yüksek çıkış yüzdesi torf ve torf + perlit $(\% 100$ ve 98$)$ ortamında elde edilmiştir.

Yetiştirme ortamlarının marul fidelerinin fide boyu ve fide yaş kuru ağırlığı üzerine etkisi istatistiksel olarak önemli $(\mathrm{p}<0.05)$ bulunmuştur (Çizelge 3). Marulda en yüksek fide boyu (8.83 $\mathrm{cm}$ ) domates atığ1 yetiştirme (DA) ortamında yetiştirilen fidelerde tespit edilmiştir. Bunu aralarında istatistiksel fark bulunmayan torf ve ÖDA ortamları izlemiştir. Marulda en yüksek fide yaş ağırlığı aralarında istatistiksel fark bulunmayan ÖDA ve DA (sirasiyla 0.91 ve $0.80 \mathrm{~g}$ ) ortamlarında elde edilmiştir. Fide boyu ve yaş ağırlıkları DA ortamında yetiştirilen fidelerde yüksek olmasına rağmen kök uzunluklarının diğer ortamlara göre daha düşük olduğu belirlenmiştir. Kök uzunluğu bakımından ortamlar arasında istatistiksel fark olmamasına rağmen, kontrol amaçlı kullanılan torf ortamında yetiştirilen fidelerin kök 


\section{Topraksız Tarımda Kullanıldıktan Sonra Açığa Çıkan Ortamların Marul ve Maydanoz Fidesi Yetiştiriciliğinde Kullanımı}

uzunluklarının $(10.58 \mathrm{~cm})$ daha fazla olduğu bulunmuştur (Çizelge 3). İstatistiki olarak önemli olmamasına rağmen en yüksek Kroma; (166.7), $\mathrm{Hue}^{\circ}(7.59)$ ve gövde çap1 $(1.56 \mathrm{~mm})$ değerleri Hindistan cevizi lifi ortamından elde edilmiştir.

Yetiştirme ortamlarının maydanoz fideleri üzerine kalite parametreleri incelendiğinde gövde çapı, fide boyu ve kök uzunluğu bakımından istatistiksel olarak önemli bulunmuştur $(\mathrm{p}<0.05)$. Yapılan incelemelerde en yüksek gövde çapı $(0.60-0.68 \mathrm{~mm})$ sirasıyla torf ve DA ortamında yetiștirilen fidelerde tespit edilmiştir.

Maydanozda en yüksek fide yaş ağırlığı $(0.113 \mathrm{~g})$ torf ortamında yetiştirilen fidelerde tespit edilmiştir. En yüksek kök uzunluğu aralarında istatistiksel fark bulunmayan torf $(8.95 \mathrm{~cm})$ ve ÖDA $(8.93 \mathrm{~cm})$ ortamlarından elde edilmiştir. Maydanozda en yüksek fide boyunun DA $(7.36 \mathrm{~cm})$ ve ÖDA $(7.13 \mathrm{~cm})$ ortamlarında olduğu belirlenmiștir. Fide kuru ağırlığı, fide yaş ağırlığı, hue, kroma ve klorofil kriterlerinde ise istatistiksel olarak önemli bulunmamıştır (Çizelge 3).

Sebze yetiştiriciliğine; yüksek gövde çapı ve yüksek kuru madde miktarına sahip olan fidelerle başlamak genel olarak yüksek verim ile sonuçlanmaktadır. Böyle fidelerin kalitelerinin yüksek olması, stres koşullarına karşı dayanımlarının yüksek olmasından kaynaklandığ 1 bildirilmektedir (Özer ve Kandemir, 2016). Çalışmamızda, elde edilen sonuçlara göre fide kuru ağırlıkları incelendiğinde istatistiki olarak önemli olmamasına rağmen en yüksek değerlerin marulda $0.063 \mathrm{~g}$ ile DA ve maydanozda 0.0093 $\mathrm{g}$ ile ÖDA ortamından elde edilmiştir. Gövde çap1 değerlerini incelediğimizde maydanozda en yüksek değerler torf $(0.68 \mathrm{~mm})$ ve DA $(0.60$ $\mathrm{mm})$ ortamından elde edilmiştir $(\mathrm{p}<0.05)$.

Çizelge 3. Yetiştirme ortamlarının marul ve maydanoz fidelerinin kalitesine etkileri

\begin{tabular}{|c|c|c|c|c|c|c|c|}
\hline \multirow[b]{2}{*}{ Parametreler } & \multicolumn{5}{|c|}{ Kullanılmış Yetiştirme Ortamlar } & \multirow{2}{*}{$\begin{array}{c}\text { Torf } \\
\text { (Kontrol) }\end{array}$} & \multirow{2}{*}{$\begin{array}{l}\% 5 \\
\text { LSD }\end{array}$} \\
\hline & $\begin{array}{l}\text { Sebze } \\
\text { Türü } \\
\end{array}$ & DA & ÖDA & $\begin{array}{l}\text { Hindistan } \\
\text { cevizi lifi }\end{array}$ & Torf + Perlit & & \\
\hline \multirow{2}{*}{ Fide boyu $(\mathrm{cm})$} & Marul & $8.83 \mathrm{a}^{*}$ & $7.83 \mathrm{ab}$ & $5.33 \mathrm{c}$ & $7.41 \mathrm{~b}$ & $8.66 \mathrm{ab}$ & 1.28 \\
\hline & Maydanoz & $7.36 \mathrm{a}^{*}$ & $7.13 \mathrm{a}$ & $3.23 \mathrm{~b}$ & $4.13 \mathrm{~b}$ & $6.63 \mathrm{ab}$ & 1.05 \\
\hline \multirow{2}{*}{ Gövde çapı (mm) } & Marul & 1.13 & 1.3 & 1.56 & 1.3 & 1.05 & ÖD \\
\hline & Maydanoz & $0.60 \mathrm{a}$ & $0.46 \mathrm{~b}$ & $0.30 \mathrm{c}$ & $0.45 \mathrm{~b}$ & $0.68 \mathrm{a}^{*}$ & 0.12 \\
\hline \multirow{2}{*}{ Kök uzunluğu (cm) } & Marul & 5.91 & 7.91 & 7.33 & 9.41 & 10.58 & ÖD \\
\hline & Maydanoz & $6.60 \mathrm{~b}$ & $8.93 \mathrm{a}$ & $9.16 \mathrm{a}$ & $7.66 \mathrm{ab}$ & $8.95 \mathrm{a}^{*}$ & 1.84 \\
\hline \multirow{2}{*}{ Fide yaş ağırlığı (g) } & Marul & $0.80 \mathrm{ab}$ & $0.91 \mathrm{a}^{*}$ & $0.42 \mathrm{c}$ & $0.53 \mathrm{c}$ & $0.71 \mathrm{~b}$ & 0.17 \\
\hline & Maydanoz & 0.102 & 0.099 & 0.079 & 0.071 & 0.113 & ÖD \\
\hline \multirow{2}{*}{ Fide kuru ağırlığı (g) } & Marul & 0.063 & 0.056 & 0.046 & 0.051 & 0.046 & ÖD \\
\hline & Maydanoz & 0.0091 & 0.0093 & 0.0063 & 0.0081 & 0.0085 & ÖD \\
\hline \multirow{2}{*}{$\mathrm{Hue}^{\mathrm{o}}$} & Marul & 146.3 & 136.2 & 166.7 & 137.2 & 147.9 & ÖD \\
\hline & Maydanoz & 137.8 & 136.8 & 135.7 & 136.4 & 137.3 & ÖD \\
\hline \multirow{2}{*}{ Kroma } & Marul & 12.27 & 15.07 & 7.59 & 19.54 & 12.25 & ÖD \\
\hline & Maydanoz & 16.98 & 18.47 & 19.72 & 19.38 & 18.02 & ÖD \\
\hline \multirow{2}{*}{$\begin{array}{l}\text { Yaprak klorofil } \\
\text { İçeriği }\end{array}$} & Marul & 8.21 & 8.66 & 8.24 & 8.71 & 8.36 & ÖD \\
\hline & Maydanoz & 10.4 & 10.6 & - & - & 7.21 & ÖD \\
\hline
\end{tabular}

*: $\mathrm{p}<0.05$. ÖD: Önemli değil, DA: Doğrudan kullanılan domates atığı, ÖDA: Ön işlem görmüş domates atığı 


\section{Topraksız Tarımda Kullanıldıktan Sonra Açığa Çıkan Ortamların Marul ve Maydanoz Fidesi Yetiştiriciliğinde Kullanımı}

Özellikle, ön işlem görmüş domates atığ1 ortamının fide kalitesi olarak ön plana çıkmasında ahır gübresi ve üre gibi organik gübrelerin etkisi olduğu düşünülmektedir. Çürük ve ark. (2020) yaptıkları çalışmalarda organik gübrelerin fide gelişimi üzerine etkisinin oldukça önemli olduğunu ortaya koymuşlardır. Bitkisel kökenli atıkların ciddi bir organik madde kaynağı olması ve içermiş oldukları bitki besin maddeleri yönünden de önemli bir potansiyele sahip olduğu birçok çalışma ile belirlenmiştir (Çıtak ve ark., 2007; Özer ve Uzun, 2013). Domates atı̆̆1 ve ön işlem görmüş domates atıklarının diğer ortamlara göre fide yaş ve kuru ağırlıkları bakımından daha yüksek olması, domates atığı ortamının organik maddece zengin olmasından kaynaklandığ1 düşünülmektedir. Benzer sonuçların elde edildiği bir çalışmada da organik ortam olan cibrenin hiyarda fide kalitesini özellikle fide kuru ağırlığı yönünde torfa göre önemli oranda artırdığı belirlenmiştir (Çinkılıç, 2008).

\section{Sonuç}

Çalışmada topraksız yetiştiricilikte domates ve marul üretiminde kullanıldıktan sonra açığa çıkan 4 ortamın marul ve maydanoz fidesi yetiştiriciliğinde yeniden kullanımı ve fide kaliteleri üzerine etkileri incelenmiştir. Özellikle fide kalitesinde belirleyici olan gövde çapı ve fide kuru ağırlığ değerleri bakımından DA ve ÖDA ortamlarının ön plana çıktığ görülmektedir. Çalıșma sonuçları topraksız yetiştiricilikte kullanıldıktan sonra açığa çıkan domates atığ1 ortam1 ve ön işlem görmüş domates atığının torf ortamına alternatif olarak marul ve maydanoz fide yetiştirme ortamı olarak kullanılabileceğini ortaya koymuştur. Ayrıca, domates atıklarının iki kez topraksız yetiştiricilikte ve sonrasında fide yetiştiriciliğinde başarılı bir şekilde kullanılmış olmasının atık yönetimine ve ekonomiye önemli katkılar sunacağı düşünülmektedir.

\section{Kaynaklar}

Atiyeh RM, Dominguez J, Subler S, Edwards CA (2000) Changes in biochemical properties of cow manure during processing by earthworms (Eisenia andrei, Bouche) and the effects on seedling growth. Pedobiologia 44:709724.

Çıtak, S., Sönmez, S., Öktüren, F. (2006) Bitkisel kökenli atıkların tarımda kullanılabilme olanakları. Derim 23(1): 40-53.

Çinkılıç, H. (2008) Farklı organik ve inorganik ortamlarda hıyar fidesi üretimi. Tekirda $\breve{g}$ Ziraat Fakültesi Dergisi 5(2):151-158.

Çürük, U. (2020) Organik ve inorganik gübre uygulamalarının karabuğdayda kök gelișimine etkisi. Toprak Su Dergisi 4145.

Demiral, M.A. (2016) Bir topraksız kültür ortam1 olarak torf. Derim 17(1):39-52.

Demirkaya, M. (2012) Ozmotik koşullandırma ve humidifikasyon uygulamalarının biber tohumlarının ortalama çıkış süresi ve çıkış oranı üzerine etkileri. Selçuk Tarım ve Glda Bilimleri Dergisi 26 (4):27-32

Doğan, D. (2003) Domates ve hiyar fidesi üretiminde yetiştirme ortamlarına katılan tavuk gübresinin fide gelişimi ve kalitesine etkileri. Ankara Üniversitesi Fen Bilimleri Enstitüsü Yüksek Lisans Tezi, 91s.

Dönmez, İ., Özer, H., Gülser, C. (2016) Bazı bölgesel organik atıkların topraksız tarımda (torba kültürü) kullanılabilme imkanlarının belirlenmesi. Anadolu Tarım Bilimleri Dergisi 31(2):171-178.

Durmuş, M., Kızılkaya, R. (2018) Domates üretim atık ve artıklarından kompost eldesi. Toprak Bilimi ve Bitki Besleme Dergisi 6(2):95-100.

Kandemir, D., Özer, H., Özkaraman F., Uzun S. (2013) The effect of different seed sowing media on the quality of cucumber seedlings. The European Journal of Plant Science and Biotechnology 7 (Special Issue 1), 66-69.

McGuire, R.G. (1992) Reporting of objective colour measurement. Hortsci 27:12541255.

Munsuz, N., Ataman, Y., Ünver, İ. (1982) Tarımda yetiştirme ortamları ve perlit. Yayin No:102, Etibank Matbaas1, Ankara. 


\section{Topraksız Tarımda Kullanıldıktan Sonra Açığa Çıkan Ortamların Marul ve Maydanoz Fidesi Yetiştiriciliğinde Kullanımı}

Namal, E.R. (2019) Fide yetiştiriciliğinde kullanılan farklı ortamların bazı fizikokimyasal özellikleri ile domates fide kalite parametrelerindeki değişimlerin belirlenmesi. Fen Bilimleri Enstitüsü, Toprak Bilimi ve Bitki Besleme Anabilim Dalı, Yüksek Lisans Tezi, 51s.

Özer, H. (2018) The effects of different seedling production systems on quality of tomato plantlets. Acta Scientiarum Polonorum-Hortorum Cultus 17(5): 1521.

Özer, H., Kandemir D. (2016) Evaluation of the performance of greenhouse tomato seedlings grown with different cultivation techniques. Bangladesh Journal of Botany 45(1):203-209.

Özer, H., Kandemir, D., Uzun, S. (2008) Domates fidelerinin kalitesi üzerine farklı fide yetiştirme ortamlarının etkisi. VII. Sebze Tarımı Sempozyumu. 315-320. 26-29 Ağustos, Yalova.

Özer, H., Uzun, S. (2013) Açıkta organik domates (Solanum lycopersicum L.) yetiştiriciliğginde farklı organik gübrelerin baz1 verim ve kalite parametrelerine etkisi. Türkiye $V$. Organik Tarm Sempozyuтu. Bildiri Kitabl-1 1-8. 25-27 Eylül, Samsun.

Peker, D., Özer, H., Eren E. (2019) Influence of peat, jiffy tablet and tomato waste spawned by Pleurotus ostreatus mycelium media on pepper seedling quality. Turkish Journal of Food and Agriculture Sciences 1(1):24-27.

Polat, S., Șahin, N., Özdemir, H. (2017) Farklı fide yetiștirme ortamlarının Crimson Sweet karpuz çeşidinde fide kalitesine etkileri. Akademik Ziraat Dergisi 6:4750.

Tüzel, Y., Gül, A., Daşgan, H.Y., Öztekin, G.B., Engindemiz, S., Boyaci, H.F. (2015) Örtüaltı yetiştiriciliğinde değişimler ve yeni arayışlar. Türkiye Ziraat Mühendisliği VIII. Teknik kongresi, Bildiriler Kitabl-I, 12- 16 Ocak, Ankara, 685-709.

Varış, S., Eminoğlu, F.S. (2003) Örtüaltı tarımında kullanılan ve kullanılabilinecek olan ortamların fiziksel ve kimyasal özellikleri. Hasad 220:46-57.

Yılmaz, C., Sırça, E., Özer, H., Pekșen, A. (2018) Agaricus ve Pleurotus atık mantar kompostlarınin domates fide üretiminde yetiştirme ortamı olarak kullanımı. Türkiye Tarımsal Araştırmalar Dergisi 5(3): 229-235.

Yörük, E. (2021) Domates atığının topraksız tarımda kullanılan ticari yetiştirme ortamlarına altarnetif olarak kullanılabilirliği Ondokuz Mayıs Üniversitesi Lisansüstü Enstitüsü Yüksek Lisans Tezi, 41s. 
Topraksız Tarımda Kullanıldıktan Sonra Açığa Çıkan Ortamların

Marul ve Maydanoz Fidesi Yetiştiriciliğinde Kullanımı 